\title{
EFFECTS OF ENDURANCE TRAINING ON FUNCTIONAL STATUS OF THE RESPIRATORY MUSCLES IN HEALTHY MEN
}

\author{
ANDRZEJ KLUSIEWICZIA, ŁUKASZ ZUBIK², BARBARA DŁUGOŁĘCKA², MAŁGORZATA CHARMAS², \\ JERZY BRONIEC ${ }^{3}$, BENEDYKT HENRYK OPASZOWSKI ${ }^{1 \mathrm{~B}}$, MICHAŁ STARCZEWSKI ${ }^{1 A}$, \\ MARIA ŁADYGA ${ }^{1 A}$
}

\author{
IInstitute of Sport - National Research Institute in Warsaw, Department of Physiology, \\ Department of Endocrinology \\ 2Józef Pitsudski University of Physical Education in Warsaw, Faculty of Physical Education and Sport \\ in Biała Podlaska, Department of Physiology and Biochemistry \\ ${ }^{3}$ Polish Rowing Association
}

\begin{abstract}
Mailing address: Andrzej Klusiewicz, Institute of Sport, Department of Physiology, 2/16 Trylogii Street, 01-982 Warsaw, tel.: +48 22 5699968, fax: +48 22 5699906, e-mail: andrzej.klusiewicz@insp.waw.pl
\end{abstract}

\begin{abstract}
Introduction. The aim of the study was to assess the influence of an 8-week endurance training program on the functional status of the respiratory muscles and breathing efficiency. Material and methods. Thirteen healthy, untrained, male students of Physical Education volunteered to participate in the study. Before and after the subjects completed the training program, they were subjected to anthropometric and spirometric measurements, and performed an incremental stress test. The spirometric measurements included maximal inspiratory pressure (PImax), active time, passive time, and diaphragm relaxation time. Measuring PImax is a simple method of evaluating the strength of the inspiratory muscles. The 8-week training program was performed on a rowing ergometer 3 times per week, using aerobic workloads. Results. The study did not confirm a significant improvement in the measured spirometric parameters following the training program. However, we observed a trend of increase in PImax values by $12 \pm 21 \%$ of borderline after the training program and a significant correlation $(\mathrm{p}<0.05)$ between the changes in PImax and those in $\mathrm{VO}_{2}$ max. Following the training there was also a significant reduction in the amount of body fat by $1.4 \mathrm{~kg}$ and an improvement of work capacity. The response of the respiratory system to exercise was also enhanced, as breathing efficiency improved (tidal volume increased in maximal exercise, while lung ventilation, the ventilatory equivalent for oxygen, and breathing frequency decreased in submaximal exercise). Conclusions. The findings of the study suggest that traditional endurance training which is implemented over a 8 weeks is not a sufficiently strong stimulus to cause a significant increase in the strength of the inspiratory muscles.
\end{abstract}

Key words: endurance training, respiratory muscle strength, aerobic capacity, breathing efficiency

\section{Introduction}

Traditional endurance training has been found to improve several key parameters of aerobic capacity, such as $\mathrm{VO}_{2}$ max, the anaerobic/ventilatory threshold, and exercise economy, enhancing the capacity for performing work for a long time without a decrease in its efficiency [1]. These changes are believed to stem from the adaptation of the cardiovascular system to increased effort, but adaptations of the respiratory system in athletes and healthy persons are seldom mentioned. As stated by Cogo [2], it is often assumed that the respiratory system does not restrict the work capacity of athletes. It is also commonly believed that the functional capacity of a healthy respiratory system, including that of the lungs, chest, and neural control systems, exceeds the demands which are imposed upon this system during strenuous effort [3].

Research shows, however, that the respiratory system (in particular restrictions in respiratory flow and diaphragm fatigue) can limit work capacity both in athletes [4] and healthy persons $[5,6]$. Bearing this in mind, experts have designed specific methods of training the respiratory muscles using simula- tors intended to help the respiratory system adapt to exercise by increasing the strength and endurance of these muscles. Several studies have confirmed that respiratory muscle training causes an increase in the strength of these muscle groups and enhances work capacity in athletes [7-11]. It has also been proven that resistance training of the respiratory muscles can serve as an additional physiological stimulus for the athlete's body in the training process. It is worth emphasizing that nearly all of the authors who have investigated this issue have found respiratory muscle training to have a positive effect on work capacity [12]

On the other hand, the impact of traditional endurance training on changes in the strength of the respiratory muscles still requires investigation, as the findings of studies regarding this issue are contradictory. A significant increase in the strength of the respiratory muscles following endurance training, assessed based on maximal inspiratory mouth pressure (PImax), was found in swimmers [13] and healthy persons [14], but no such increase was observed in athletes practicing various endurance disciplines compared to persons who are not physically active [15-18]. However, our previous study [19] showed that highly trained athletes had higher PImax values af- 
ter undergoing endurance training compared to persons whose physical activity was moderate. These data have led us to formulate the hypothesis that if endurance training is organized and implemented in an appropriate way, it should increase the strength of the respiratory muscles and the values of other parameters reflecting the functional status of the respiratory muscles, such as inspiratory time (including active and passive time) and diaphragm relaxation time. It was assumed that an effective training stimulus would be rowing which engaged $70 \%$ of the skeletal muscles and had considerable cardiorespiratory effects $[11,20]$. We chose workloads which elicited 60-85\% HRmax, as they were expected to improve both aerobic capacity [21] and the strength of the respiratory muscles. The aim of the current study was to assess the effects of an 8-week endurance training program not only on changes in work capacity but also on the functional status of the respiratory muscles and breathing efficiency.

\section{Material and methods}

The study involved 13 untrained healthy students of Physical Education. The characteristics of the participants are presented in Table 1.

Table 1. Characteristics of the untrained healthy men before (Pretest) and after (Posttest) completing the 8-week endurance training program on the rowing ergometer $(n=13)$

\begin{tabular}{|l|c|c|}
\hline \multicolumn{1}{|c|}{ Variable } & Pretest & Posttest \\
\hline Age (years) & $20.4 \pm 0.6$ & \\
\hline Height $(\mathrm{cm})$ & $181.2 \pm 5.9$ & \\
\hline Weight $(\mathrm{kg})$ & $79.8 \pm 11.9$ & $78.8 \pm 11.4$ \\
\hline BMl $\left(\mathrm{kg} / \mathrm{m}^{2}\right)$ & $24.0 \pm 2.2$ & $23.7 \pm 2.3$ \\
\hline Fat mass $(\mathrm{kg})$ & $11.6 \pm 4.1$ & $10.2 \pm 3.8^{*}$ \\
\hline Fat percentage $(\%)$ & $14.0 \pm 3.4$ & $12.4 \pm 3.6^{*}$ \\
\hline Fat-free mass $(\mathrm{kg})$ & $67.0 \pm 9.7$ & $69.0 \pm 8.7$ \\
\hline
\end{tabular}

$*=\mathrm{p}<0.05$.

The subjects were informed about the design of the study and about the risk and discomfort that might occur. They then signed an informed consent form. The study was conducted according to the Declaration of Helsinki (1975) and was approved by the Senate Research Ethics Committee of the University of Physical Education in Warsaw, Poland. Before and after the subjects completed the training program, anthropometric and spirometric measurements and stress tests were performed.

\section{Endurance training program}

The specially designed 8-week endurance training program was implemented using the Concept 2 ergometer (Morrisville, USA) in the form of 3 training sessions per week. The duration of each training session was 60-70 minutes. The training program was preceded by 2-3 introductory sessions aimed at helping the subjects develop a correct rowing technique. All of the sessions were supervised by an instructor.

Before the sessions, the subjects performed an incremental stress test to exhaustion. The data obtained in the study made it possible to determine the individual range of training loads corresponding to a heart rate (HR) amounting to $60-85 \%$ of the HRmax of a given subject. An outline of the training program is presented in Table 2 . The program was designed by the coach of the Polish National Rowing Team.

Table 2. Outline of the 8-week endurance training program on the rowing ergometer

\begin{tabular}{|c|c|c|}
\hline \multirow{2}{*}{ Week 1} & Session 1 & $\begin{array}{l}\text { 2' arms only - 2' trunk and arms - 2' } 1 / 4 \text { slide - } \\
\text { 6' full slide, repeated } 4-5 \text { times, with a } 4-5^{\prime} \\
\text { break (intensity: } 60-65 \% \text { HRmax) }\end{array}$ \\
\hline & Sessions 2 and 3 & $\begin{array}{l}\text { 2' arms only - 2' trunk and arms - 2' } 1 / 4 \text { slide, } \\
3-4 \times 10^{\prime}, 3^{\prime} \text { breaks }(60-70 \% \text { HRmax })\end{array}$ \\
\hline \multirow{2}{*}{ Week 2} & Sessions 1 and 2 & $\begin{array}{l}\text { 2' arms only }-2 \text { ' trunk and arms }-2{ }^{\prime} 1 / 4 \text { slide - } \\
\text { 6' full slide, } 3 \times 15^{\prime} \text {, with varying intensity (2'l } \\
70 \% \text { HRmax; } 3 \text { '/ } 60 \% \text { HRmax) }\end{array}$ \\
\hline & Session 3 & $\begin{array}{l}\text { 2' arms only }-2 \text { ' trunk and arms }-2{ }^{\prime} 1 / 4 \text { slide - } \\
\text { 6' full slide, } 3 \times 15^{\prime} \text { with varying intensity (3'/ } \\
70 \% \text { HRmax; 3' } 60 \% \text { HRmax) }\end{array}$ \\
\hline Week 3 & Sessions 1-3 & $\begin{array}{l}\text { 10' warm-up, 4' break, } 15^{\prime} \text { (5'/ } 60 \% \text { HRmax; } 5^{\prime} \text { l } \\
70 \% \text { HRmax; 5'/ 75\% HRmax) }\end{array}$ \\
\hline \multirow{2}{*}{ Week 4} & Sessions 1 and 2 & $\begin{array}{l}1 \times 20^{\prime}\left(5^{\prime} 60 \% \text { HRmax; } 10^{\prime} / 70 \% \text { HRmax; 5'/ }\right. \\
60 \% \text { HRmax) } \\
1 \times 30^{\prime}(65-70 \% \text { HRmax })\end{array}$ \\
\hline & Session 3 & $\begin{array}{l}\text { 10' warm-up, 4' break, } 1 \text { x } 45^{\prime}(70-75 \% \\
\text { HRmax), } 1 \text { x } 15^{\prime}\left(5^{\prime} / 65 \% \text { HRmax; 5' } 60 \%\right. \\
\text { HRmax; 5'/55\% HRmax) }\end{array}$ \\
\hline \multirow{2}{*}{$\begin{array}{l}\text { Weeks } \\
5-8\end{array}$} & Sessions 1 and 2 & $\begin{array}{l}1 \times 20^{\prime}\left(5^{\prime} / 60 \% \text { HRmax; } 10^{\prime} / 70 \% \text { HRmax; 5'/ }\right. \\
60 \% \text { HRmax), } \\
1 \times 30^{\prime}(70-75 \% \text { HRmax })\end{array}$ \\
\hline & Session 3 & $\begin{array}{l}\text { 10' warm-up, 4' break, } 1 \text { x 45' }(75-85 \% \\
\text { HRmax), } 1 \text { x } 15\left(5^{\prime} / 70 \% \text { HRmax; 5'/ } 65 \%\right. \\
\text { HRmax; 5'/ 60\% HRmax) }\end{array}$ \\
\hline
\end{tabular}

' = minutes; $\mathrm{HRmax}=$ maximal heart rate.

\section{Anthropometric measurements}

The anthropometric data recorded included the height and weight of the subjects. The amount of body fat and fat-free mass were assessed by means of a bioimpedance (BIA) body fat analyzer (Tanita model BC-418 MA, Japan).

\section{Spirometric measurements}

The subjects were made familiar with the methods and procedure used in the study, and all the measurements were performed by the same technician. Maximal inspiratory mouth pressure (PImax) was measured using a procedure described by several authors; this is a simple, reproducible, and non-invasive method of evaluating the strength of the inspiratory muscles [7, $19,22-24]$. A minimum of 10 and a maximum of 15 inspiratory maneuvers were performed. The three highest values, which varied by no more than $5 \%$, were established as the maximum. The initial position of the inspiratory muscles was controlled by having the subjects expire up to the residual volume (RV) before the measurement. All of the measurements were performed in a standing position. The subjects were verbally motivated to exert maximal effort. The measurement points which were used are shown in Figure 1. 


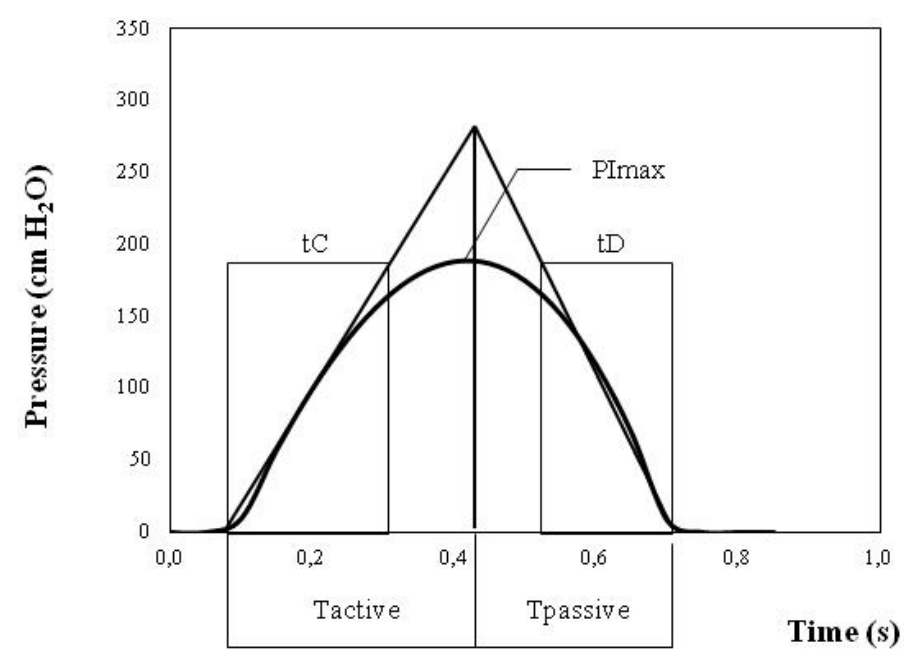

Figure 1. Curve for the changes in inspiratory pressure during vigorous inspiration with measuring points

The following data were recorded:

- active time (Tactive) - the segment of the time axis between the point of intersection of the tangents projected onto the time axis and the intersection of the tangent for the rising part of the curve with the time axis;

- passive time (Tpassive) - the segment of the time axis between the point of intersection of the tangents projected onto the time axis and the intersection of the tangent for the falling part of the curve with the time axis;

- inspiratory time (Tin);

- diaphragm relaxation time (tD) - the time it takes for the negative pressure to fall from its highest value (PImax) to zero (PIo).

The PImax and PIo points were calculated based on the tangent for the middle segment $(50-80 \%)$ of the relaxation time curve. It is worth emphasizing that our previous research [22] has proven the reproducibility of the method that was used to measure the spirometric parameters mentioned above (we found no statistically significant differences between repeated measurements, as well as significant correlations and a total error rate of 11 to $24 \%$ for all of the spirometric parameters examined).

The measurements were performed using a spirometer which was compatible with Lungtest 1000 software (MES, Cracow, Poland). The apparatus transmitted the pressure from the measurement site (the mouthpiece) to the pressure sensors.

\section{Stress tests}

The subjects performed an incremental stress test on the Concept 2 rowing ergometer (Morrisville, USA) until exhaustion. The damper was set to 4-6. The test consisted of several trials lasting 3 minutes, with 1-minute breaks between the trials. The power used in the initial trial was $80 \mathrm{~W}$, and it was increased by $40 \mathrm{~W}$ in each successive trial. The initial rowing speed was 16 strokes/minute, and the speed was increased by 2 strokes/minute with each successive trial. The changes in the work capacity caused by the endurance training were assessed based on the subjects' reactions to submaximal exercise (with a power of $160 \mathrm{~W}$ ) and the values of the parameters recorded during maximal exercise.

Lactate concentrations (LA) were measured in the blood collected from the earlobe immediately after the subjects com- pleted each trial and 3 minutes after the entire test was completed, using the Super GL 2 device (Dr Müller, Germany). Respiratory exchange parameters were recorded continuously in a breath-by-breath (B x B) mode using a Cortex 3B MetaLyzer (Cortex Biophysik GmbH, Germany) over the entire duration of the test. Heart rate (HR) was recorded using a Polar S610i heart rate monitor (Electro Oy, Finland).

\section{Statistical analysis}

For the purposes of the statistical analysis, we calculated the mean values and standard deviations (SD) of the data. The differences between the mean values were analyzed using the Wilcoxon signed-rank test for dependent samples and Pearson's correlation coefficent was calculated. The calculations and statistical analysis were performed using Statistica 10 (StatSoft).

\section{Results}

The endurance training program caused a reduction in the amount of body fat by an average of $1.4 \mathrm{~kg}$, as shown in Table 1 . The spirometric parameters measured in the study did not improve significantly, although all the parameters of work capacity apart from the lactate concentration measured after the test did improve, Table 3 and 4 . The greatest changes were observed for the amount of work performed normalized to body mass $(30 \pm$ $18 \%)$, the duration of the test $(17 \pm 10 \%)$, and $\mathrm{VO}_{2}$ max normalized to body mass $(7 \pm 9 \%)$.

Table 3. Changes in maximal inspiratory mouth pressure (PImax), inspiratory time (Tin), active time (Tactive), passive time (Tpassive), and diaphragm relaxation time $(\mathrm{tD})$ recorded for the untrained students before (Pretest) and after (Posttest) the 8-week endurance training program on the rowing ergometer $(n=13)$

\begin{tabular}{|l|c|c|}
\hline \multicolumn{1}{|c|}{ Variable } & Pretest & Posttest \\
\hline PImax $\left(\mathrm{cm} \mathrm{H}_{2} \mathrm{O}\right)$ & $114 \pm 15$ & $128 \pm 26^{\text {ns }}$ \\
\hline Tin $(\mathrm{ms})$ & $645 \pm 123$ & $679 \pm 113^{\text {ns }}$ \\
\hline Tactive $(\mathrm{ms})$ & $260 \pm 42$ & $293 \pm 69^{\text {ns }}$ \\
\hline Tpassive $(\mathrm{ms})$ & $226 \pm 51$ & $250 \pm 66^{\text {ns }}$ \\
\hline tD $(\mathrm{ms})$ & $124 \pm 28$ & $126 \pm 33^{\text {ns }}$ \\
\hline
\end{tabular}

$\mathrm{ns}=\mathrm{p}>0.05$.

Table 4. Changes in work capacity recorded for the untrained healthy men before (Pretest) and after (Posttest) the 8-week endurance training program on the rowing ergometer $(n=13)$

\begin{tabular}{|l|c|c|}
\hline \multicolumn{1}{|c|}{ Variable } & Pretest & Posttest \\
\hline Test duration (min:s) & $14: 50 \pm 2: 56$ & $17: 24 \pm 03: 00^{*}$ \\
\hline Work performed in the test $(\mathrm{KJ})$ & $145.7 \pm 46.5$ & $186.9 \pm 55.2^{*}$ \\
\hline Work performed in the test $(\mathrm{KJ} / \mathrm{kg})$ & $1.80 \pm 0.44$ & $2.34 \pm 0.51^{*}$ \\
\hline $\mathrm{VO}_{2}$ max $(\mathrm{l} / \mathrm{min})$ & $3.52 \pm 0.52$ & $3.71 \pm 0.59^{*}$ \\
\hline $\mathrm{VO}_{2} \mathrm{max}(\mathrm{ml} / \mathrm{kg} / \mathrm{min})$ & $44.0 \pm 4.2$ & $46.9 \pm 5.0^{*}$ \\
\hline Lactate concentration $(\mathrm{mmol} / \mathrm{l})$ & $13.5 \pm 2.7$ & $13.1 \pm 2.0$ \\
\hline
\end{tabular}

${ }^{*}=\mathrm{p}<0.05$. 
The ventilatory response to the stress test was characterized by increased tidal volume in maximal exercise and decreased lung ventilation in standard submaximal exercise $(160 \mathrm{~W})$, along with a lower ventilatory equivalent for oxygen and lower breathing frequency, as shown in Table 5. The metabolic response to submaximal exercise also improved, which was proven by the decrease in lactate concentration measured after the test (Tab. 5).

Table 5. Changes in pulmonary ventilation (VE), the ventilatory equivalent for oxygen $\left(\mathrm{VE} / \mathrm{VO}_{2}\right)$, breathing frequency $(\mathrm{BF})$, tidal volume (Vt), and heart rate (HR) recorded for maximal and submaximal exercise (for the power of $160 \mathrm{~W}$ ) in the untrained healthy men before (Pretest) and after (Posttest) the 8-week endurance training program on the rowing ergometer $(n=13)$

\begin{tabular}{|c|c|c|}
\hline Parameter & Pretest & Posttest \\
\hline VEmax (I/min) & $132.7 \pm 19.3$ & $139.4 \pm 23.0$ \\
\hline $\mathrm{VE} / \mathrm{VO}_{2} \max$ & $36.1 \pm 2.2$ & $35.7 \pm 3.3$ \\
\hline BFmax (breaths/min) & $55 \pm 9$ & $53 \pm 10$ \\
\hline Vtmax (I) & $2.39 \pm 0.27$ & $2.62 \pm 0.34^{*}$ \\
\hline $\mathrm{VE}_{160}(1 / \mathrm{min})$ & $86.7 \pm 11.0$ & $73.8 \pm 10.9^{*}$ \\
\hline $\mathrm{VO}_{2160}(1 / \mathrm{min})$ & $2.78 \pm 0.16$ & $2.66 \pm 0.26$ \\
\hline $\mathrm{VO}_{2160}(\mathrm{ml} / \mathrm{kg} / \mathrm{min})$ & $35.2 \pm 3.9$ & $34.1 \pm 5.7$ \\
\hline $\mathrm{VE} / \mathrm{VO}_{2160}$ & $29.1 \pm 4.4$ & $25.7 \pm 3.0^{*}$ \\
\hline $\mathrm{BF}_{160}$ (breaths/min) & $39 \pm 7$ & $32 \pm 6^{*}$ \\
\hline $\mathrm{Vt}_{160}(\mathrm{I})$ & $2.27 \pm 0.29$ & $2.31 \pm 0.29$ \\
\hline $\mathrm{HR}_{160}(\mathrm{bpm})$ & $178 \pm 13$ & $166 \pm 15^{*}$ \\
\hline Lactate concentration 160 (mmol/l) & $5.99 \pm 2.51$ & $4.15 \pm 2.23^{*}$ \\
\hline
\end{tabular}

$*=p<0.05$.

\section{Discussion}

Contrary to expectations, the study did not confirm a significant improvement in the examined spirometric parameters (Tactive, Tpassive, and Tin) following the endurance train-

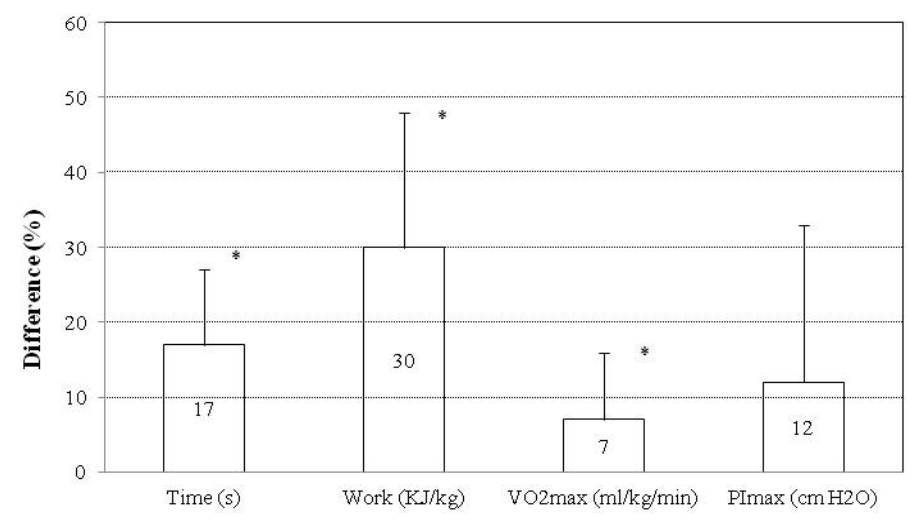

${ }^{*}=\mathrm{p}<0.05$.

Figure 2. Changes in test duration, work performed in the test, maximal oxygen uptake $\left(\mathrm{VO}_{2} \max \right)$, and maximal inspiratory pressure (PImax): differences between the values recorded for the untrained healthy men before and after the 8-week endurance training program on the rowing ergometer (delta \%) ing program, although PImax values increased by $12 \pm 21 \%$, as shown in Figure 2.

Moreover, it was found that the strength of the respiratory muscles increased after the training was implemented, which is evidenced by the correlation between changes in $\mathrm{VO}_{2}$ max and PImax $(r=0.652, p<0.05)$ presented in Figure 3.

Considering the findings of similar research, authors such as Coast et al. [16] and Hanel et al. [25] did not observe an increase in respiratory muscle strength as a result of endurance training on a cycle ergometer or in the form of cross-country skiing. Cordain et al. [17], Armour et al. [15], and Estwood et al. [18] found no significant differences in PImax between swimmers, cross-country runners, and marathon runners and the control groups (untrained subjects). Nor were significant correlations revealed between PImax and $\mathrm{VO}_{2}$ max in moderately trained men McConnell et al. [26]. Our previous research [19] also showed that endurance training performed by highly trained persons may not help further develop the strength of the respiratory muscles and that the relationships between PImax and other variables are not direct and depend on the subject's gender. These observations have been confirmed by the findings of the current study. The hyperventilation the subjects experienced during training sessions on a rowing ergometer which were held only for a few weeks was not a sufficiently strong stimulus to cause an improvement in respiratory muscle strength. According to Eastwood et al. [18], long-lasting endurance training is more likely to induce "sensory" changes than cause the respiratory muscles to adapt to increased effort.

However, the study by Clanton et al. [13] delivered different findings in this respect: 12 weeks of swimming training resulted in a significant increase in the strength and endurance of the respiratory muscles. The research carried out by Dunham and Harms [14] also revealed a significant improvement in PImax in physically active, healthy subjects who underwent 4 weeks of endurance training with constant intensity and those who engaged in interval training. PImax values in their study were observed to have increased by 25 and 43\%, respectively, and the improvement was significantly higher in subjects who had performed interval training. We would argue that such a high in-

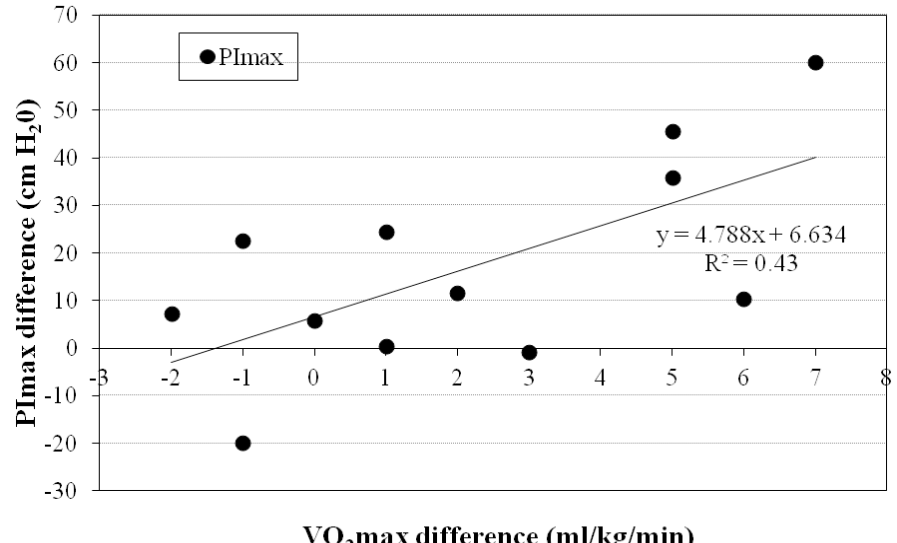

Figure 3. Linear relationship between the changes in maximal oxygen uptake $\left(\mathrm{VO}_{2}\right.$ max) and the changes in maximal inspiratory pressure (PImax) recorded for the untrained healthy men after the 8-week endurance training program on the rowing ergometer $(n=12)$ 
crease in PImax could have been caused by the subjects' low initial PImax, since, similarly as in the case of $\mathrm{VO}_{2}$ max, a negative correlation has been found between the initial PImax value and the increase in PImax after inspiratory muscle training [27, 28]

At this point, it is difficult to explain the reason for differences in the reactions of various subjects to traditional endurance training reflected in their PImax, and more research needs to be conducted in order to clarify this issue. Undoubtedly, the level of fitness of the subjects as well as the type, intensity, and duration of the training play a vital role.

As could have been expected, the controlled 8-week endurance training program used in the current study caused positive changes in some of the subjects' body components, as the amount of body fat was reduced and work capacity improved. We also observed significant increases in the duration of the stress test until exhaustion, the amount of work performed, and maximal oxygen uptake, by 17,30 , and $7 \%$, respectively. The high increase in the work performed stemmed not only from the significant improvement in maximal oxygen uptake and exercise economy, but also from a considerable increase of the anaerobic component of energy expenditure. This is proven by the high maximal lactate concentration in the blood, which was as high as the one recorded before the training program started (13.5 and $13.1 \mathrm{mmol} / \mathrm{l}$, respectively). A similar metabolic reaction to a stress test performed until exhaustion was observed by Santtila et al. [29], also after an 8-week endurance training program, in young men aged $19.2 \pm 0.9$ years (the lactate concentration was $13.2 \pm 2.1 \mathrm{mmol} / \mathrm{l}$ before the training program and $13.1 \pm 1.6 \mathrm{mmol} / \mathrm{l}$ after the training program). It is worth noting that such a high lactate concentration at the moment when a subject stops the test due to exhaustion is one of the most important criteria for achieving maximal oxygen uptake [29], and it proves that the subject is highly motivated to perform the test and participate in the entire research study.

The improvement in $\mathrm{VO}_{2}$ max of $6.6 \%$ found in the current study was slightly higher than the $5.6 \%$ improvement observed in healthy men who completed an 8-week endurance training program in addition to doing military training [30]. The higher increase in our study may be due to a relatively low $\mathrm{VO}_{2}$ max in our subjects $(44.0 \pm 4.2 \mathrm{ml} / \mathrm{kg} / \mathrm{min}$ in our subjects vs. $46.4 \pm$ $7.9 \mathrm{ml} / \mathrm{kg} / \mathrm{min}$ in the military recruits). Dunkan and Harms [14] observed an improvement in $\mathrm{VO}_{2}$ max in physically active, healthy men and women of $5.5 \%$ after just 4 weeks of endurance training, a finding that was also likely a consequence of a low initial level of $\mathrm{VO}_{2} \max (32.5 \mathrm{ml} / \mathrm{kg} / \mathrm{min})$. Indeed, several studies have shown that $\mathrm{VO}_{2}$ max tends to improve more the lower it is before the training program begins [31-33]).

On the other hand, some research has revealed greater increases in $\mathrm{VO}_{2}$ max than those observed in our study. Carter et al. [34] found that $\mathrm{VO}_{2}$ max increased by $10 \%$ in physical education students after 6 weeks of endurance training (in the form of 3-5 sessions per week lasting 20-30 minutes), and Hickson et al. [35] observed a $14 \%$ increase in $\mathrm{VO}_{2}$ max after 3 weeks of endurance training (6 sessions per week lasting 40 minutes). The results of these studies suggest that the lower increase in $\mathrm{VO}_{2}$ max in our study could have been due to a lower number of individual training sessions per week and that aerobic capacity is better stimulated when training sessions are held more often (and for a shorter period of time) rather than less often and for a longer period of time (in the current study the subjects trained 3 times a week for 60 minutes).

One of the expected effects of endurance training is the enhancement of exercise economy, which is defined as the oxygen uptake $\left(\mathrm{VO}_{2}\right)$ required at a given absolute exercise intensity [1].
When our subjects performed submaximal/standard exercise (with a power of $160 \mathrm{~W}$ ), we observed lower oxygen uptake, although lung ventilation, the ventilatory equivalent for oxygen, and breathing frequency were significantly lower (Tab. 5). The difficulty the subjects had in developing an appropriate rowing technique on an ergometer, as this is known to be one of the many factors that have an impact on exercise economy $[36,37]$. What makes rowing on an ergometer difficult is the fact that in order to ensure proper ventilation, it is necessary to synchronize one's breathing with the phases of rowing (the catch, drive, finish, and recovery). This is related to the work of the respiratory muscles, which are responsible not only for the respiratory exchange, but also for controlling the position of the body and stabilizing the chest [38-40]. Breathing is typically adjusted to the rowing cycle according to the following ratios: 1:1, 2:1 and 3:1 [41]. The 1:1 breathing pattern is composed of 1 inspiration in the drive phase and 1 expiration in the recovery phase, and this is how the best rowers breathe when rowing. Observations from sports practice confirm that it takes a rower approximately 8 months of rowing training to adjust to a selected breathing pattern $[42,43]$. Since the assessment of the economy of submaximal exercise in our study was performed after only 8 weeks of training, it can be assumed that the subjects had not yet learned how to breathe according to an individual breathing pattern. It should be emphasized that the respiratory muscles also contribute to stabilizing the trunk, which has an impact on the strength used in the driving phase. Not having an individual breathing pattern could have been the reason why the demand of the respiratory muscles for energy did not decrease significantly.

\section{Practical applications}

According to the findings of the study, a traditional 8-week endurance training program on a rowing ergometer aimed at stimulating large muscle groups during rowing is not sufficient for the strength of the inspiratory muscles to improve in untrained healthy men. This has important practical implications, since if a considerable increase in the strength of these muscles is to be achieved in a short time (in only a few weeks), specific resistance training of the inspiratory muscles, involving the use of special devices, needs to be implemented.

\section{Acknowledgements}

This research project (RSA2 003 52) was funded by the Polish Ministry of Science and Higher Education from the budget for science for the years 2013-2016. All the tests were conducted in the Regional Center for Research and Development in Biała Podlaska, Laboratory of Physiological Diagnosis.

\section{Literature}

1. Jones A.M., Carter H. (2000). The effect of endurance training on parameters of aerobic fitness. Sports Medicine 29(6), 373-386.

2. Cogo A. (2014). Lung, not only heart. Multidisciplinary Respiratory Medicine 9(1), 21. DOI: 10.1186/2049-6958-9-21.

3. Guenette J.A., Sheel A.W. (2007). Physiological consequences of a high work of breathing during heavy exercise in humans. Journal of Science and Medicine in Sport 10(6), 341350. DOI: 10.1016/j.jsams.2007.02.003.

4. Mota S., Casan P., Drobnic F., Giner J., Ruiz O., Sanchis J. et al. (1999). Expiratory flow limitation during exercise in 
competition cyclists. Journl of Applied Physiology 86(2), 611-616.

5. Dempsey J.A., McKenzie D.C., Haverkamp H.C., Eldridge M.W. (2008). Update in the understanding of respiratory limitations to exercise performance in fit, active adults. Chest 134(3), 613-622. DOI: 10.1378/chest.07-2730.

6. Olafsson S., Hyatt R.E. (1969). Ventilatory mechanics and expiratory flow limitation during exercise in normal subjects. The Journal of Clinical Investigation 48(3), 564-573. DOI: $10.1172 /$ JCI106015.

7. Fuso L., Di Cosmo V., Nardecchia B., Sammarro S., Pagliari G., Pistelli R. (1996). Maximal inspiratory pressure in elite soccer players. The Journal of Sports Medicine and Physical Fitness 36(1), 67-71.

8. Klusiewicz A., Borkowski L., Zdanowicz R., Boros P., Wesolowski S. (2008). The inspiratory muscle training in elite rowers. The Journal of Sports Medicine and Physical Fitness 48(3), 279-284.

9. Lomax M., Grant I., Corbett J. (2011). Inspiratory muscle warm-up and inspiratory muscle training: Separate and combined effects on intermittent running to exhaustion. Journal of Sports Sciences 29(6), 563-569. DOI: 10.1080/02640414.2010.543911.

10. Romer L.M., McConnell A.K., Jones D.A. (2002). Effects of inspiratory muscle training on time-trial performance in trained cyclists. Journal of Sports Sciences 20(7), 547-562. DOI: $10.1080 / 026404102760000053$.

11. Volianitis S., Mcconnell A.K., Koutedakis Y., Mcnaughton L., Backx K., Jones D.A. (2001). Inspiratory muscle training improves rowing performance. Medicine and Science in Sports and Exercise 33(5), 803-809.

12. Riganas C.S., Vrabas I.S., Christoulas K., Mandroukas K. (2008). Specific inspiratory muscle training does not improve performance or $\mathrm{VO}_{2}$ max levels in well trained rowers. The Journal of Sports Medicine and Physical Fitness 48(3), 285-92.

13. Clanton T.L., Dixon G.F., Drake J., Gadek J.E. (1987). Effects of swim training on lung volumes and inspiratory muscle conditioning. Journal of Applied Physiology 62(1), 39-46.

14. Dunham C., Harms C.A. (2012). Effects of high-intensity interval training on pulmonary function. European Journal of Applied Physiology 112(8), 3061-3068. DOI: 10.1007/ s00421-011-2285-5.

15. Armour J., Donnelly P.M., Bye P.T. (1993). The large lungs of elite swimmers: An increased alveolar number? European Respiratory Journal 6(2), 237-247.

16. Coast J.R., Clifford P.S., Henrich T.W., Stray-Gundersen J., Johnson R.L. (1990). Maximal inspiratory pressure following maximal exercise in trained and untrained subjects. Medicine and Science in Sports and Exercise 22(6), 811-815.

17. Cordain L., Tucker A., Moon D., Stager J.M. (1990). Lung volumes and maximal respiratory pressures in collegiate swimmers and runners. Research Quarterly for Exercise and Sport 61(1), 70-74. DOI: 10.1080/02701367.1990.10607479.

18. Eastwood P.R., Hillman D.R., Finucane K.E. (2001). Inspiratory muscle performance in endurance athletes and sedentary subjects. Respirology 6(2), 95-104. DOI: 10.1046/j. 1440-1843.2001.00314.x.

19. Klusiewicz A., Zubik L., Długolecka B., Charmas M. (2014). Characteristics of the respiratory muscle strength of women and men at different training levels. Polish Journal of Sport and Tourism 21(2), 82-86. DOI: 10.2478/pjst-2014-0008.

20. Mejuto G., Arratibel I., Cámara J., Puente A., Iturriaga G., Calleja-González J. (2012). The effect of a 6-week indi- vidual anaerobic threshold based programme in a traditional rowing crew. Biology of Sport 29(4), 297-301. DOI: 10.5604/20831862.1019886.

21. Seiler S. (2012). Training intensity distribution. In I. Mujika (ed.), Endurance training - science and practice (pp. 29-39). Vitoria-Gasteiz Basque Country: Inigo Mujika S.L.U.

22. Klusiewicz A. (2008). Characteristics of the inspiratory muscle strength in well trained athletes. Biology of Sport 25, 13-22.

23. Romer L.M., McConnell A.K. (2004). Inter-test reliability for non-invasive measures of respiratory muscle function in healthy humans. European Journal of Applied Physiology 91(2-3), 167-176. DOI: 10.1007/s00421-003-0984-2.

24. Wen A.S., Woo M.S., Keens T.G. (1997). How many maneuvers are required to measure maximal inspiratory pressure accurately. Chest 111(3), 802-807.

25. Hanel B., LevineB.D., Engfred K., Clifford P.S., Friedman D.B., Secher N.H. (1994). Maximal inspiratory pressure following endurance training at altitude. Ergonomics 37(1), 59-67. DOI: $10.1080 / 00140139408963623$.

26. McConnell A.K., Caine M.P., Sharpe G.R. (1997). Inspiratory muscle fatigue following running to volitional fatigue: The influence of baseline strength. International Journal of Sports Medicine 18(3), 169-173. DOI: 10.1055/s-2007972614.

27. Brown P.I., Johnson M.A., Sharpe G.R. (2014). Determinants of inspiratory muscle strength in healthy humans. Respiratory Physiology \& Neurobiology 196, 50-55. DOI: 10.1016/j. resp.2014.02.014.

28. Winkler G., Zifko U., Nader A., Frank W., Zwick H., Toifl K. et al. (2000). Dose-dependent effects of inspiratory muscle training in neuromuscular disorders. Muscle E Nerve 23(8), 1257-1260.

29. Santtila M., Keijo H., Laura K., Heikki K. (2008). Changes in cardiovascular performance during an 8-week military basic training period combined with added endurance or strength training. Military Medicine 173(12), 1173-1179.

30. Howley E.T., Bassett D.R.J., Welch H.G. (1995). Criteria for maximal oxygen uptake: Review and commentary. Medicine and Science in Sports and Exercise 27(9), 1292-1301.

31. Hickson R.C., Rosenkoetter M.A. (1981). Reduced training frequencies and maintenance of increased aerobic power. Medicine and Science in Sports and Exercise 13(1), 13-16.

32. Legg S.J., Duggan A. (1996). The effects of basic training on aerobic fitness and muscular strength and endurance of British Army recruits. Ergonomics 39(12), 1403-1418. DOI: 10.1080/00140139608964560.

33. Santtila M. (2010). Effects of added endurance or strength training on cardiovascular and neuromuscular performance of conscripts during the 8-week basic training period. Doctoral thesis, University of Jyväskylä, Finland.

34. Carte H., Jones A.M., Doust J.H. (1999). Effect of 6 weeks of endurance training on the lactate minimum speed. Journal of Sports Sciences 17(12), 957-967. DOI: 10.1080/026404199365353.

35. Hickson R.C., Hagberg J.M., Ehsani A.A., Holloszy J.O. (1981). Time course of the adaptive responses of aerobic power and heart rate to training. Medicine and Science in Sports and Exercise 13(1), 17-20.

36. Saunders P.U., Pyne D.B., Telford R.D., Hawley J.A. (2004). Factors affecting running economy in trained distance runners. Sports Medicine 34(7), 465-485. DOI: 10.2165/00007256-200434070-00005. 
37. Williams K.R., Cavanagh P.R. (1987). Relationship between distance running mechanics, running economy, and performance. Journal of Applied Physiology 63(3), 1236-1245.

38. Griffiths L.A., McConnell A.K. (2012). The influence of rowing-related postures upon respiratory muscle pressure and flow generating capacity. European Journal of Applied Physiology 112(12), 4143-4150. DOI: 10.1007/s00421-0122399-4.

39. Lazovic B., Mazic S., Suzic-Lazic J., Djelic M., DjordjevicSaranovic S., Durmic T. et al. (2015). Respiratory adaptations in different types of sport. European Review for Medical and Pharmacological Sciences 19(12), 2269-2274.

40. Mahler D.A., Hunter B., LentineT., Ward J. (1991). Locomotorrespiratory coupling develops in novice female rowers with training. Medicine and Science in Sports and Exercise 23(12), 1362-1366.

41. Steinacker J.M., Both M., Whipp B.J. (1993). Pulmonary mechanics and entrainment of respiration and stroke rate during rowing. International Journal of Sports Medicine 14, 15-19.

42. Siegmund G.P., Edwards M.R., Moore K.S., Tiessen D.A., Sanderson D.J., McKenzie D.C. (1999). Ventilation and locomotion coupling in varsity male rowers. Journal of Applied Physiology 87(1), 233-242.

43. Mahler D.A., Shuhart C.R., Brew E., Stukel T.A. (1991). Ventilatory responses and entrainment of breathing during rowing. Medicine and Science in Sports and Exercis 23(2), 186-192.

Submitted: August 24, 2017

Accepted: October 19, 2017 